Article

\title{
The Effect of Pressure and Solvent on the Supercritical Fluid Chromatography Separation of Tocol Analogs in Palm Oil
}

\author{
Mei Han $\mathrm{Ng}$ * and Ahmad Kushairi \\ Engineering and Processing Research Division, Malaysian Palm Oil Board, 6, Persiaran Institusi, \\ Bandar Baru Bangi, Kajang 43000, Selangor, Malaysia; kushairi@mpob.gov.my \\ * Correspondence: meihan@mpob.gov.my; Tel.: +603-8769-4813; Fax: +603-8926-2971
}

Received: 21 June 2017; Accepted: 16 August 2017; Published: 29 August 2017

\begin{abstract}
There are six tocol analogs present in palm oil, namely $\alpha$-tocopherol $(\alpha-T), \alpha$-tocomonoenol $\left(\alpha-T_{1}\right), \alpha$-tocotrienol $\left(\alpha-T_{3}\right), \gamma$-tocotrienol $\left(\gamma-T_{3}\right), \beta$-tocotrioenol $\left(\beta-T_{3}\right)$ and $\delta$-tocotrienol $\left(\delta-T_{3}\right)$. These analogs were difficult to separate chromatographically due to their similar structures, physical and chemical properties. This paper reports on the effect of pressure and injection solvent on the separation of the tocol analogs in palm oil. Supercritical $\mathrm{CO}_{2}$ modified with ethanol was used as the mobile phase. Both total elution time and resolution of the tocol analogs decreased with increased pressure. Ethanol as an injection solvent resulted in peak broadening of the analogs within the entire pressure range studied. Solvents with an eluent strength of 3.4 or less were more suitable for use as injecting solvents.
\end{abstract}

Keywords: palm; supercritical fluid chromatography; tocol analogs; tocotrienol

\section{Introduction}

There are six types of tocols in palm oil, namely $\alpha$-tocopherol $(\alpha-\mathrm{T}), \alpha$-tocomonoenol $\left(\alpha-\mathrm{T}_{1}\right)$, $\alpha$-tocotrienol $\left(\alpha-\mathrm{T}_{3}\right), \gamma$-tocotrienol $\left(\gamma-\mathrm{T}_{3}\right), \beta$-tocotrioenol $\left(\beta-\mathrm{T}_{3}\right)$ and $\delta$-tocotrienol $\left(\delta-\mathrm{T}_{3}\right)[1-8]$. All these tocols are structural analogs. They have a common chromanol structure with different side chains. Tocopherol has a saturated side chain, tocomonoenol is mono-unsaturated, while tocotrienol has three unsaturated bonds at its side chain. The alpha, beta, gamma or delta forms, on the other hand, are determined by the type and position of the methyl group substituent in the main chromanol structure (Figure 1).

The tocol analogs exhibit similar physical, chemical, biochemical and pharmacological properties $[1,8,9]$. Most often, these tocol analogs cannot be distinguished due to their high physical and chemical property similarity.

Supercritical fluid chromatography (SFC) is a highly efficient technique for the separation of otherwise chromatographically challenged compounds. SFC is a powerful separation technique, incorporating the high diffusivity, low viscosity and high solvating power of gas chromatography (GC) and high performance liquid chromatography (HPLC) [4,10-12]. The unique properties of a supercritical fluid as a mobile phase overcome the difficulties of solute thermal instability and volatility encountered in GC and also shorten the relatively long analyses times of HPLC separations [10,12-14]. SFC is particularly known for its superior separation of chiral compounds in terms of speed and resolution [11,15-17].

SFC has been used in the past for analyses of palm oil components [4,6,18-21]. SFC of carotenes, vitamin $\mathrm{E}$ and sterols has also been reported in the past using model mixtures. However, it is noteworthy that SFC separations are very different in a real world sample matrix compared to model matrixes where interferences from other compounds were eliminated. Choo et al. reported 
a straightforward SFC protocol, in terms of elution, squalene, carotenes, vitamin E and sterols, from real palm oil samples in a single run [4].<smiles>Cc1c(C)c2c(c(C)c1O)CCC(C)(CCCC(C)CCCC(C)CCCC(C)C)O2</smiles>

$\alpha$-Tocopherol<smiles>CC(C)=CCC/C(C)=C/CC/C(C)=C/CCC1(C)CCc2c(C)c(O)c(C)c(C)c2O1</smiles>

$\alpha$-Tocotrienol<smiles>CC(C)=CCC/C(C)=C/CC/C(C)=C/CCC1(C)CCc2cc(O)c(C)c(C)c2O1</smiles>

$\gamma$-Tocotrienol<smiles>CC(C)=CCC/C(C)=C/CC/C(C)=C/CCC1(C)CCc2cc(O)cc(C)c2O1</smiles>

$\delta$-Tocotrienol<smiles>CC(C)=CCC/C(C)=C/CC/C(C)=C/CCC1(C)CCc2c(C)c(O)cc(C)c2O1</smiles>

$\beta$-Tocotrienol<smiles>CC(C)=CCCC(C)CCCC(C)CCCC1(C)CCc2c(C)c(O)c(C)c(C)c2O1</smiles>

$\alpha$-Tocomonoenol

Figure 1. Molecular structure of tocol analogs found in palm oil. 
SFC for palm-based solutes is often carried out with supercritical $\mathrm{CO}_{2}$ as the mobile phase. $\mathrm{CO}_{2}$ is a non-polar solvent, and consequently needs an organic modifier to facilitate the elution of more polar solutes. Peaks eluted from lower to higher polarity in a normal stationary phase under such mobile phase. Most SFC applications in the early days involved the separation of non-polar solutes and homologue series. SFC is thus thought to be a suitable chromatographic tool for the separation of the tocol analogs in palm oil. The tocol analogs are readily dissolved in non-polar to moderate polarity organic solvents. Ideally chromatographic samples should be dissolved in the mobile phase to avoid addition of a third solvent. However, the tocols do not dissolve in ethanol, which is the modifier in the SFC separation. Thus, it is interesting to know the effect of different injecting solvents in SFC. This is because each solvent has its own eluent strength, which is a measure of the solvent adsorption energy, with the value for pentane defined as 0 on bare silica. The more polar the solvent, the greater is its eluent strength and the more rapidly will solutes be eluted from the column. The effect of pressure on the SFC separation of the tocol analogs was also studied and reported in this study.

\section{Results}

Supercritical $\mathrm{CO}_{2}$ modified with ethanol is able to elute all the tocol analogs present in palm oil. The elution of the tocol analogs on the silica column follows the order of $\alpha-T, \alpha-T_{1}, \alpha-T_{3}, \beta-T_{3}, \gamma-T_{3}$ and $\delta-T_{3}$ (Figures 2-6).
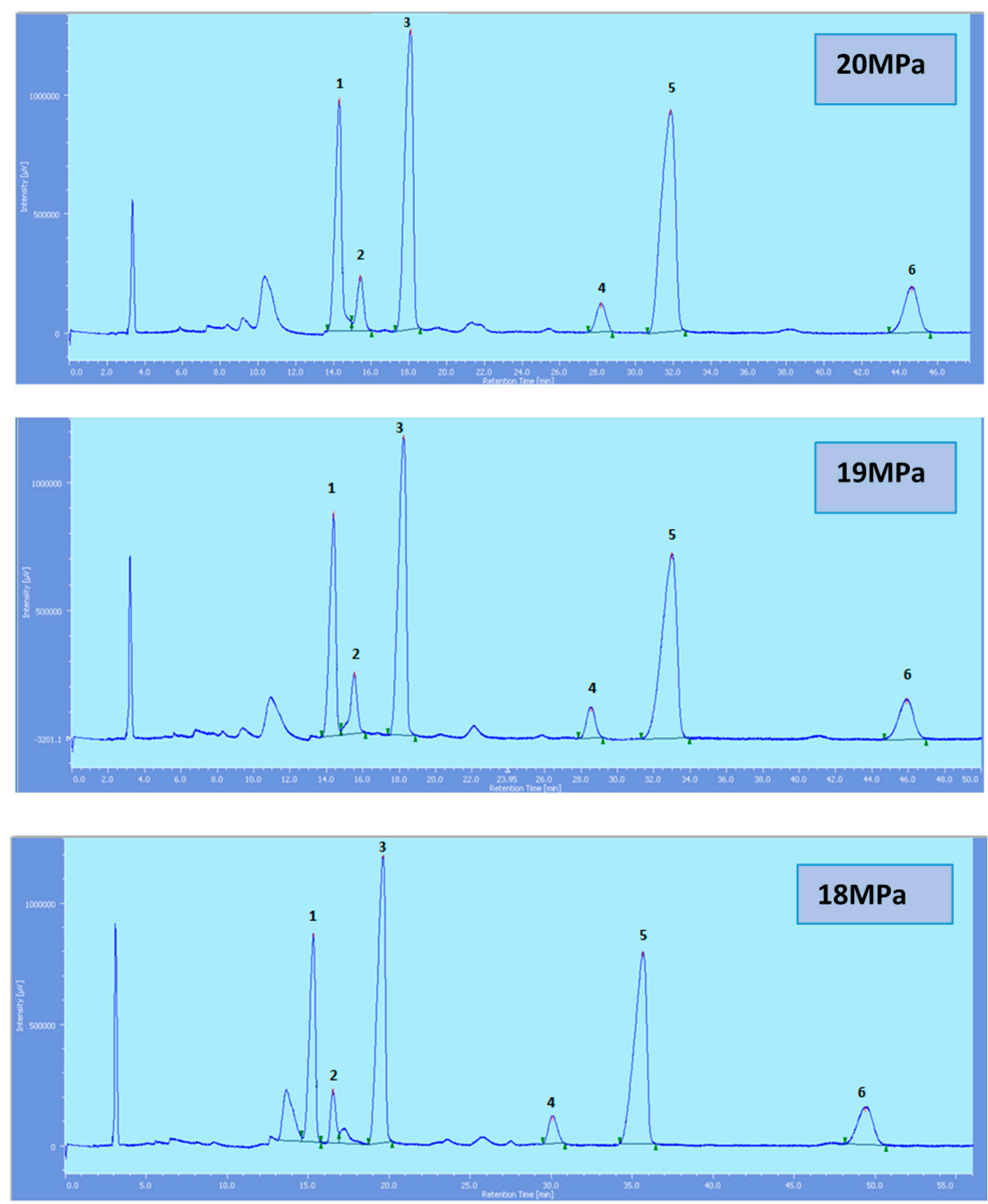

Figure 2. Cont. 


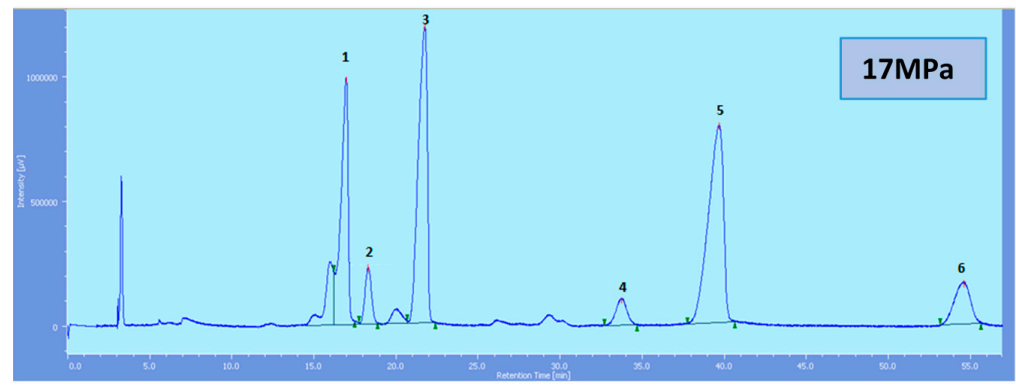

Figure 2. SFC of tocols dissolved in $n$-heptane. 1: $\alpha-\mathrm{T}, 2: \alpha-\mathrm{T}_{1}, 3: \alpha-\mathrm{T}_{3}, 4: \beta-\mathrm{T}_{3}, 5: \gamma-\mathrm{T}_{3}, 6: \delta-\mathrm{T}_{3}$.
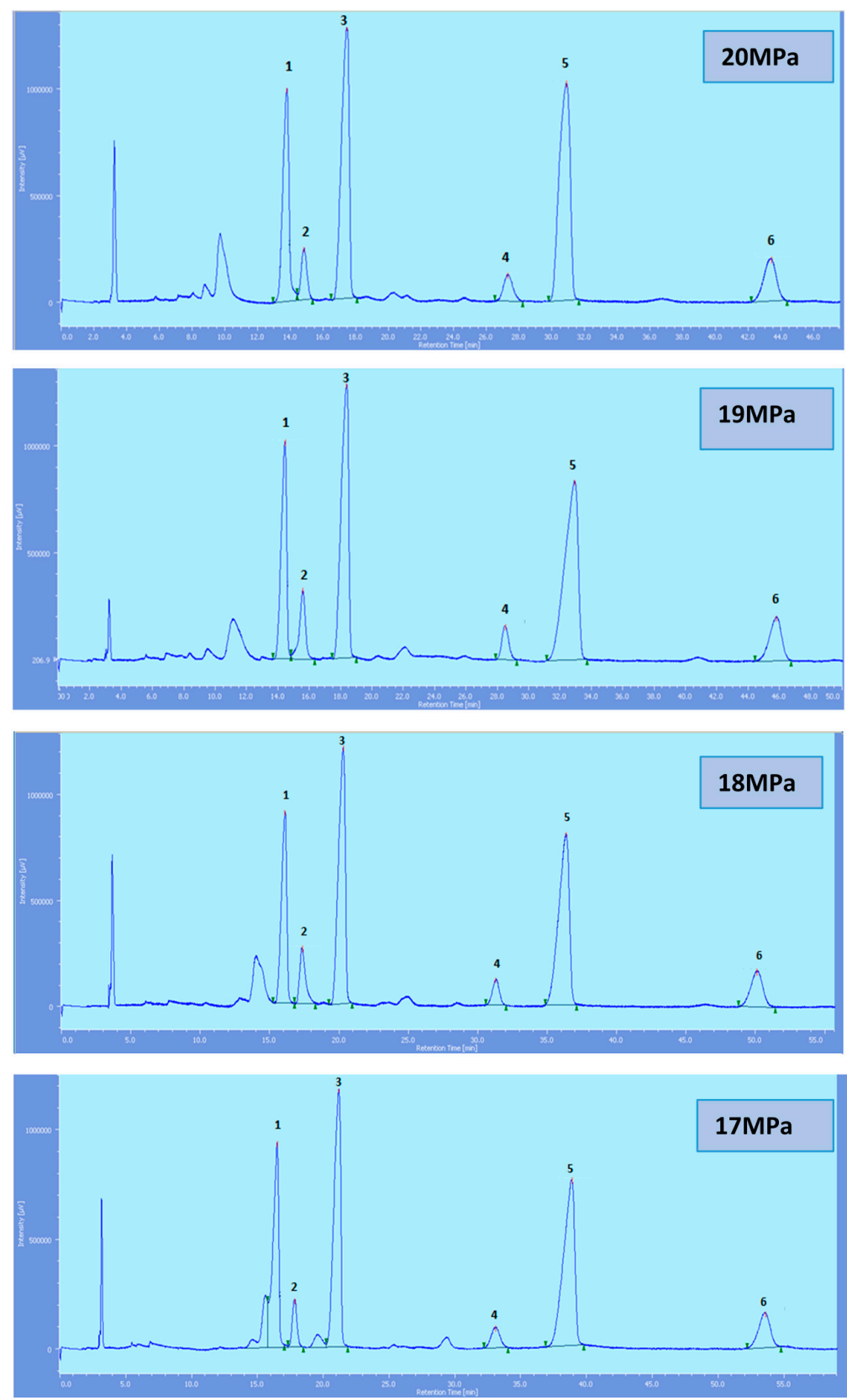

Figure 3. SFC of tocols dissolved in $n$-hexane. 1: $\alpha-T, 2: \alpha-T_{1}, 3: \alpha-T_{3}, 4: \beta-T_{3}, 5: \gamma-T_{3}, 6: \delta-T_{3}$. 

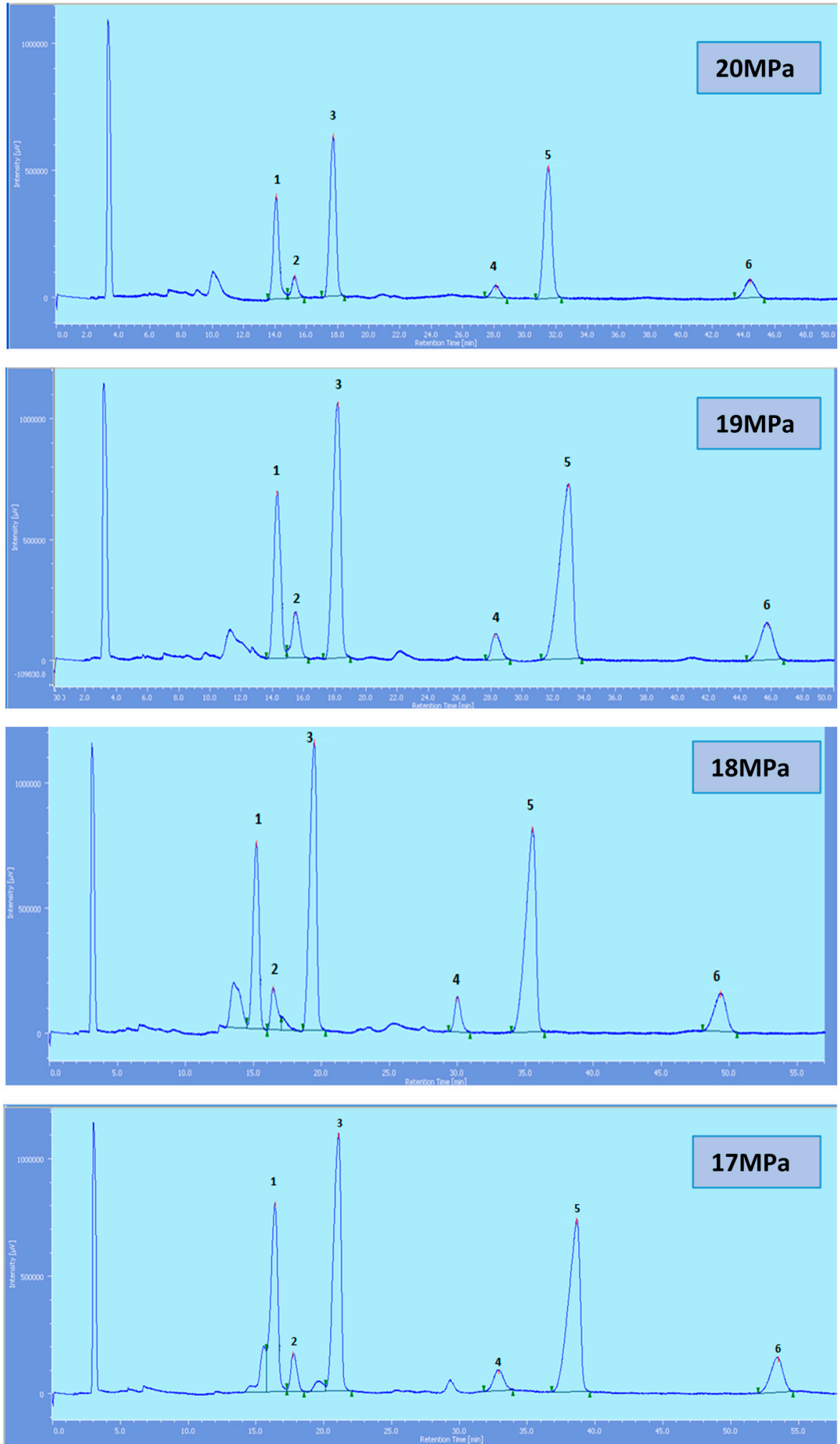

Figure 4. SFC of tocols dissolved in DCM. 1: $\alpha-\mathrm{T}, 2: \alpha-\mathrm{T}_{1}, 3: \alpha-\mathrm{T}_{3}, 4: \beta-\mathrm{T}_{3}, 5: \gamma-\mathrm{T}_{3}, 6: \delta-\mathrm{T}_{3}$. 

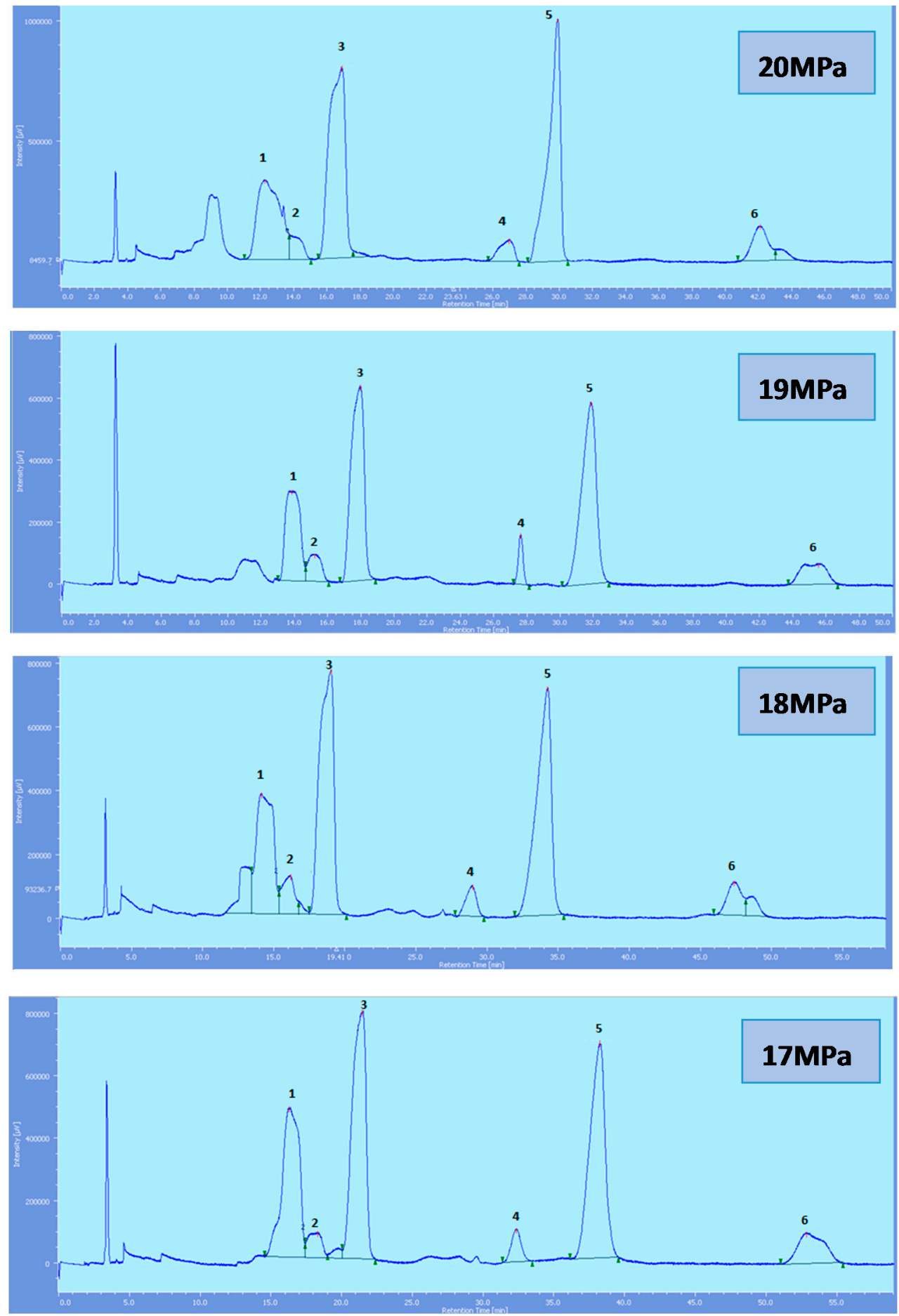

Figure 5. SFC of tocols dissolved in ethanol. 1: $\alpha-T, 2: \alpha-T_{1}, 3: \alpha-T_{3}, 4: \beta-T_{3}, 5: \gamma-T_{3}, 6: \delta-T_{3}$. 

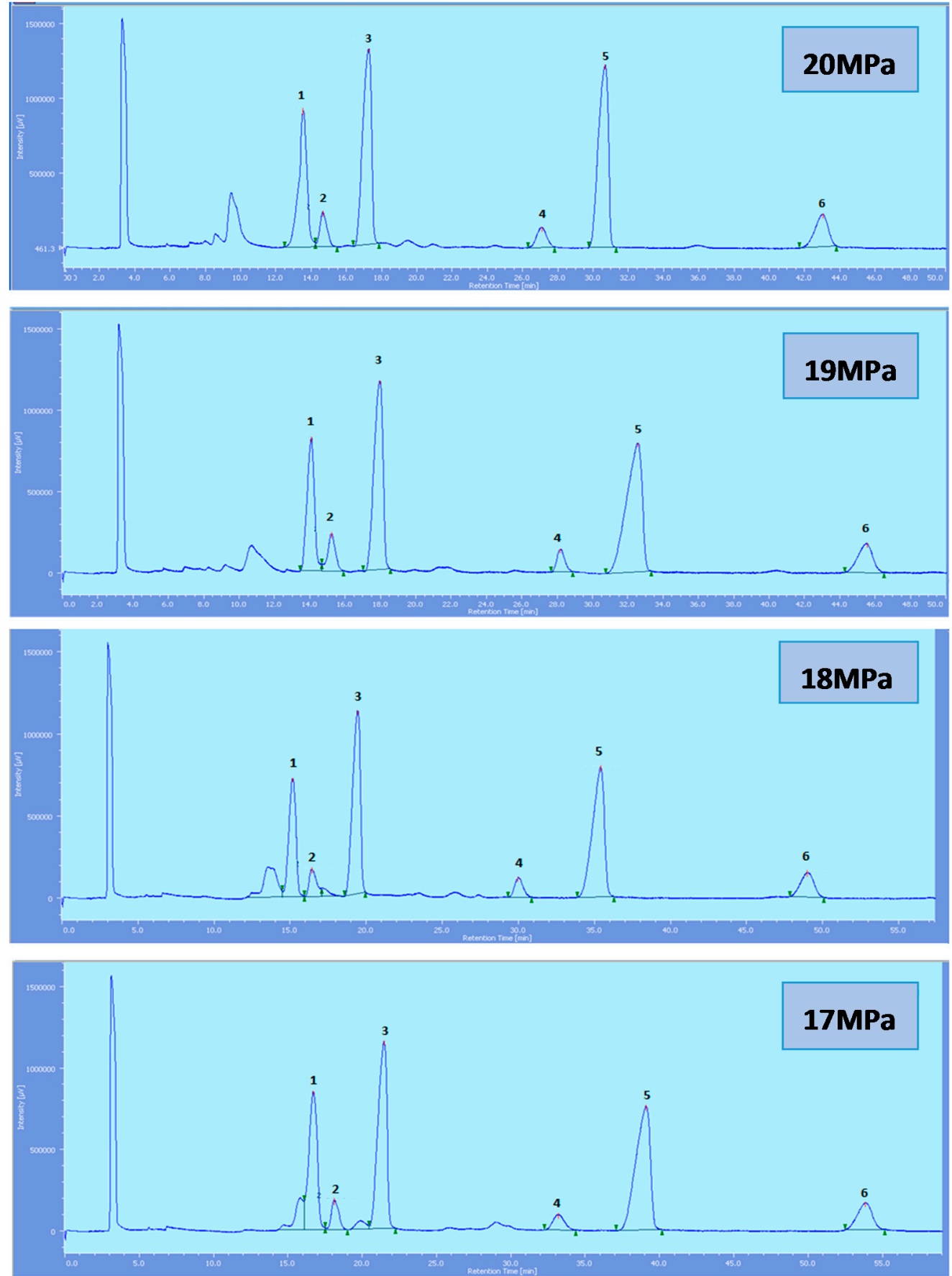

Figure 6. SFC of tocols dissolved in chloroform. 1: $\alpha-\mathrm{T}, 2: \alpha-\mathrm{T}_{1}, 3: \alpha-\mathrm{T}_{3}, 4: \beta-\mathrm{T}_{3}, 5: \gamma-\mathrm{T}_{3}, 6: \delta-\mathrm{T}_{3}$.

All the tocol analogs in palm oil are well resolved in SFC, however, baseline resolution between the $\alpha-T / \alpha-T_{1}$ peaks was lost when the pressure was increased. Increase in pressure also resulted in a shorter elution time. Capacity factor, $\mathrm{k}^{\prime}$, decreased with increasing pressure as depicted in Figures 7-10.

Table 1 shows the resolution of the $\alpha \mathrm{T} / \alpha \mathrm{T}_{1}$ prepared in different injecting solvents, at different pressure while Table 2 shows the total elution time for the tocol analogs at different pressure. 


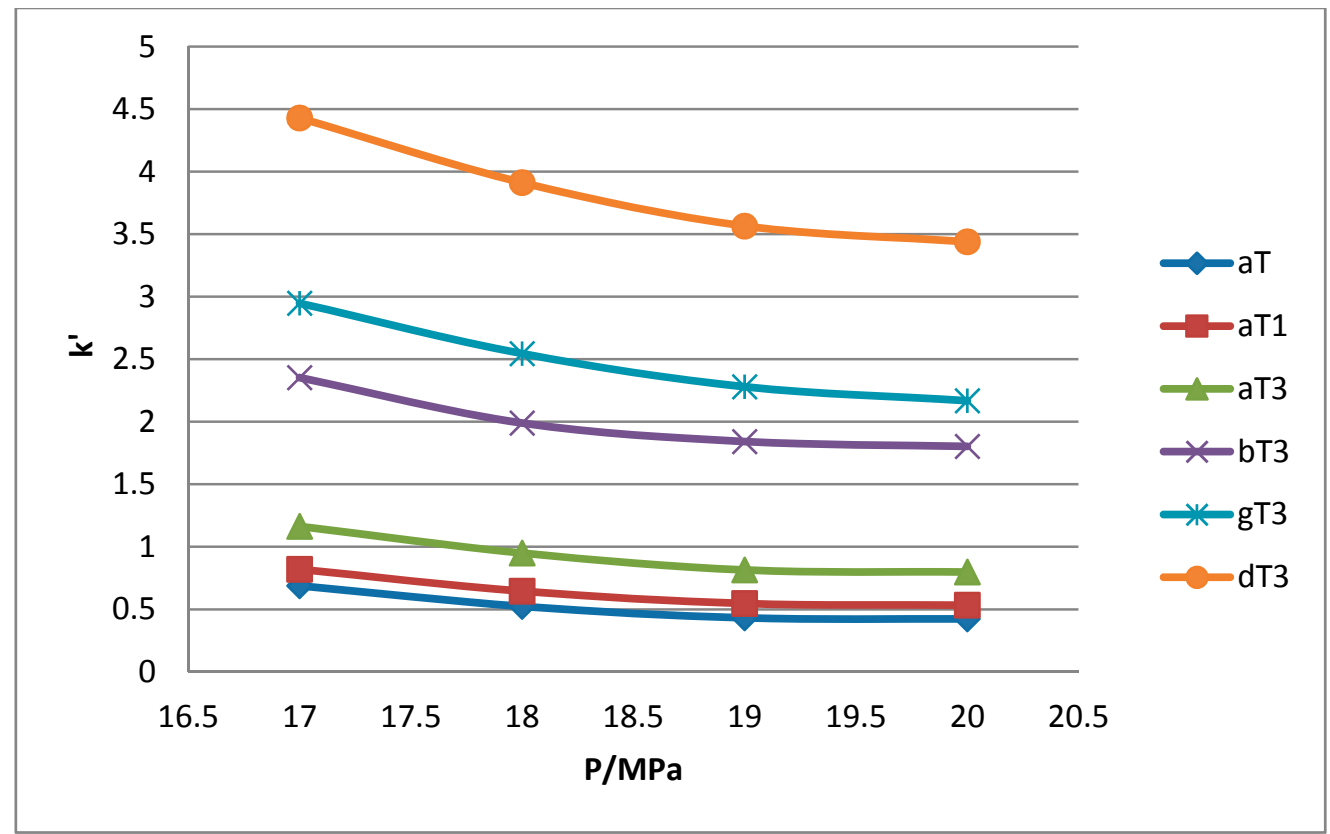

Figure 7. Effect of pressure on capacity factor for tocols dissolved in $n$-heptane.

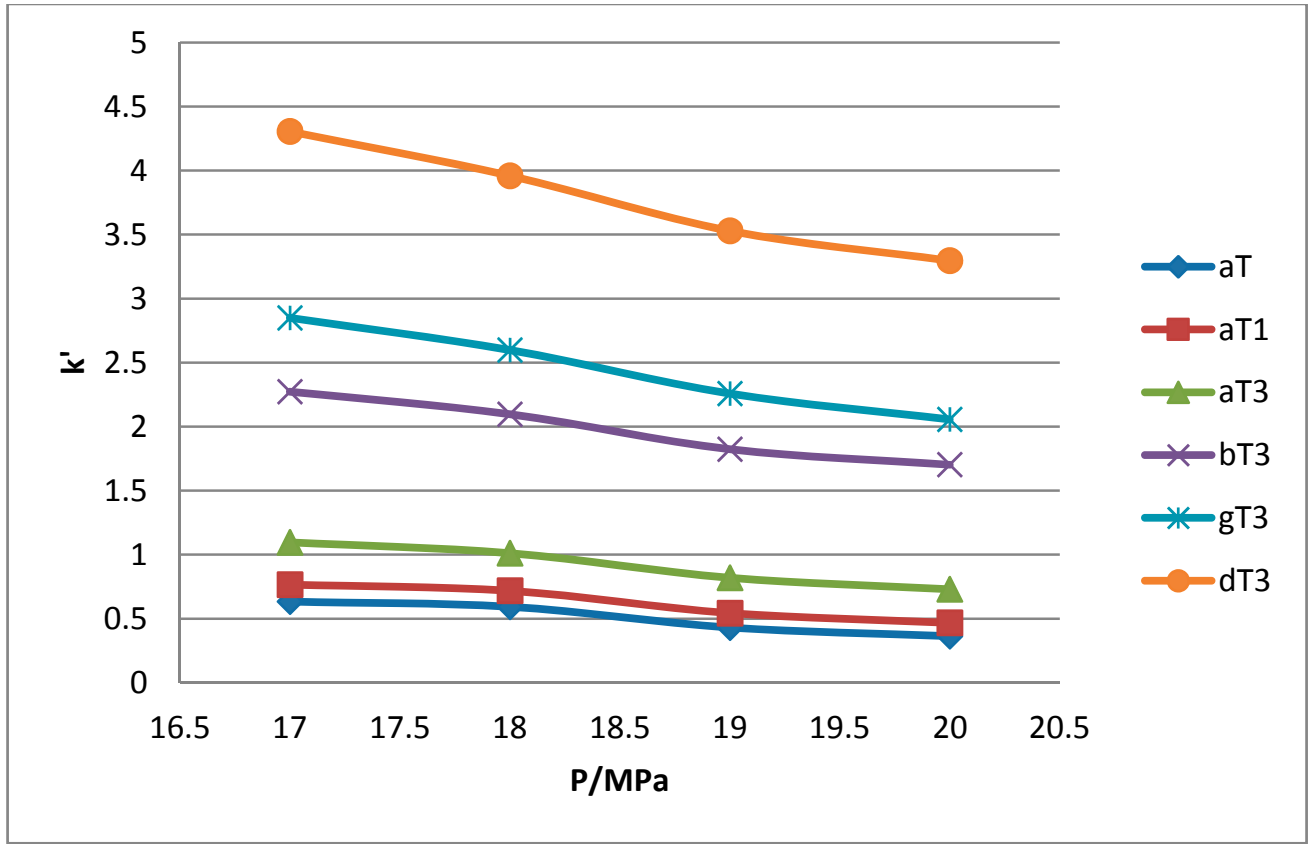

Figure 8. Effect of pressure on capacity factor for tocols dissolved in $n$-hexane.

Table 1. Resolution between alpha-T and alpha- $\mathrm{T}_{1}$ at different pressure in samples dissolved in various injecting solvents.

\begin{tabular}{cccccc}
\hline \multirow{2}{*}{ Pressure (MPa) } & \multicolumn{5}{c}{ Injecting Solvent } \\
\cline { 2 - 5 } & Heptane & Hexane & DCM & EtOH & Chloroform \\
\hline 17 & 1.106 & 1.099 & 0.978 & 0.907 & 0.973 \\
18 & 1.058 & 0.827 & 0.949 & 1.249 & 0.978 \\
19 & 0.955 & 0.854 & 0.864 & 0.916 & 0.910 \\
20 & 0.942 & 0.870 & 1.000 & 0.726 & 0.758 \\
\hline
\end{tabular}




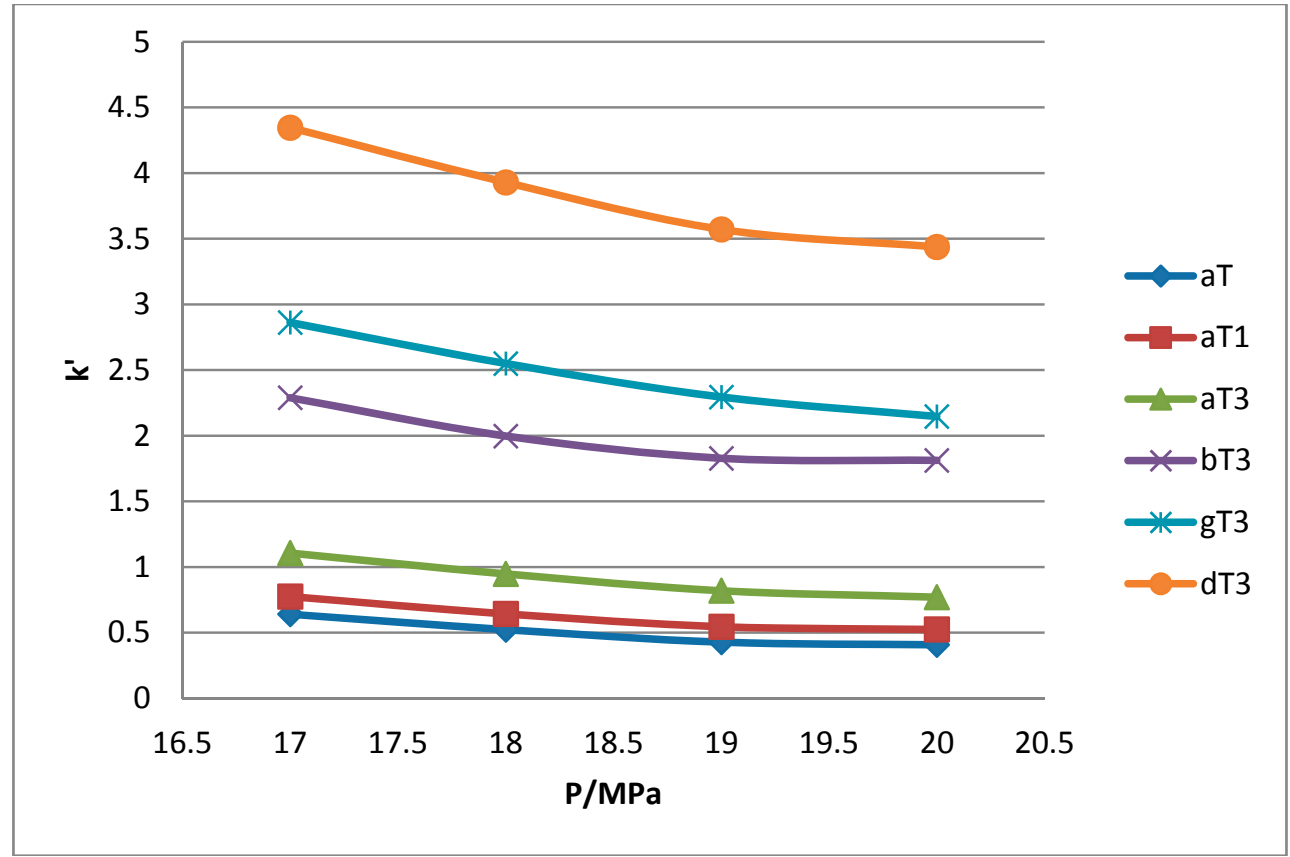

Figure 9. Effect of pressure on capacity factor for tocols dissolved in dichloromethane.

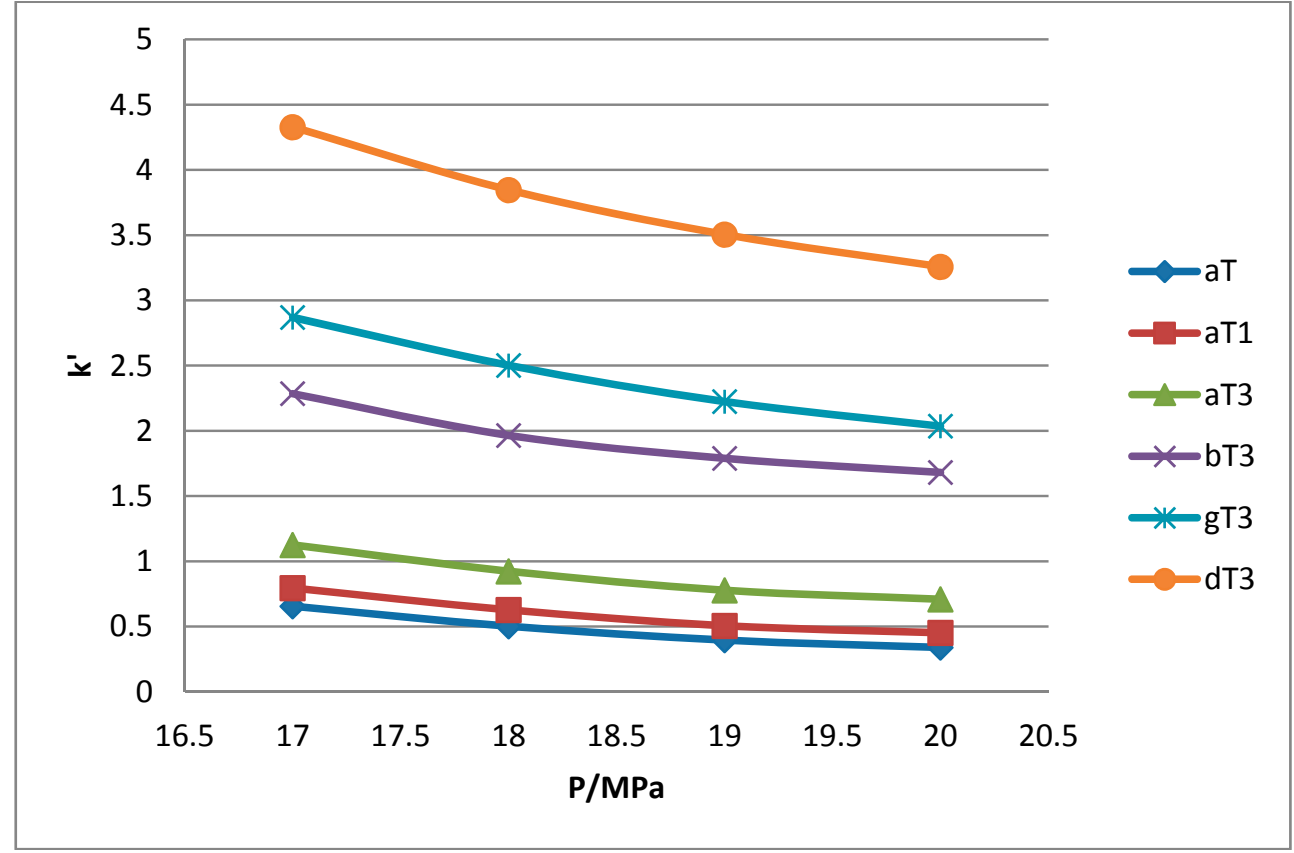

Figure 10. Effect of pressure on capacity factor for tocols dissolved in chloroform.

Table 2. Total elution time for tocols at different pressure in samples dissolved in various injecting solvents.

\begin{tabular}{cccccc}
\hline \multirow{2}{*}{ Pressure (MPa) } & \multicolumn{5}{c}{ Injecting Solvent } \\
\cline { 2 - 6 } & Heptane & Hexane & DCM & EtOH & Chloroform \\
\hline 17 & 55 & 55 & 55 & 55 & 55 \\
18 & 51 & 52 & 50 & 48 & 50 \\
19 & 47 & 47 & 47 & 47 & 47 \\
20 & 46 & 44 & 46 & 44 & 44 \\
\hline
\end{tabular}




\section{Discussion}

All the tocol analogs present in palm oil are eluted by supercritical $\mathrm{CO}_{2}$ modified with ethanol. The elution order of the tocol analogs was that the saturated analog eluted first, followed by the analogs in the order of increasing unsaturation. In normal phase chromatography, the polarity of the mobile phase and solute are the factors which determine the elution order. In this study, supercritical $\mathrm{CO}_{2}$, modified with a small percentage of an entrainer helped to elute the tocol analogs of moderate polarity.

Generally, samples for chromatographic analyses are dissolved in the same solvent as the mobile phase. In SFC, the mobile phase is a supercritical fluid. As such, samples are dissolved in other pre-selected solvents or the same solvent as a modifier. In this study, the mobile phase was modified with ethanol. Injecting solvents of moderate polarity or eluent strength such as hexane, heptane, dichloromethane and chloroform did not have a significant effect on the peak shapes of any of the tocol analogs. However, peak broadening was observed when ethanol was used as an injecting solvent. This was somewhat unexpected as the mobile phase itself contains ethanol. On the other hand, introducing a third component into the mobile phase in the form of injecting solvent did not have any effect on the SFC separation.

Solvents of eluent strength up to 3.4 are suitable for the use as injecting solvents when preparing the tocol analogs sample for SFC. Although in minimal amount, the high eluent strength of the injecting solvent does play a role in determining the peak shape and separation of the tocol analogs in palm oil.

The retention of the tocol analogs in SFC is described by the capacity factor, $\mathrm{k}^{\prime} . \mathrm{k}^{\prime}$ is expressed as $k^{\prime}=\left(t_{r}-t_{0}\right) / t_{0}$ where $t_{r}$ is the retention time of the tocol while $t_{0}$ is the dead time of the column, measured as the elution time of the injecting solvent. The injecting solvent was hardly retained on the column and thus, its retention time is used as the dead time $\left(t_{0}\right)$ in the calculation of the capacity factor. By keeping the temperature constant, the effect of pressure on the separation of the analogs can be clearly seen. It was observed that the capacity factors decreased with increasing pressure. The mobile phase is more compressible at a low pressure, resulting in a high capacity factor. The density of the mobile phase increases with pressure, thus enhancing the solubility of the solute in the mobile phase which, in turn, results in lower retention.

While the rest of the tocols are well separated, the $\alpha \mathrm{T} / \alpha \mathrm{T}_{1}$ pair was not very well resolved and this is of particular interest where the effect of pressure is a concern. Generally, the resolution decreases with the increase in pressure. However, the pair is still well resolved up to $20 \mathrm{MPa}$. The total eluting time decreases with the increase of pressure as shown in Table 2. The density of mobile phase increases with pressure, resulting in a higher solubility of the tocol analogs in supercritical $\mathrm{CO}_{2}$. This in turn, facilitated the elution of the tocol analogs from the stationary phase, hence lower resolution and shorter elution time are observed.

\section{Materials and Methods}

\subsection{Materials}

All solvents used were of chromatographic grade, purchased from Merck (Darmstadt, Germany). Tocols were purchased from Carotino (M). Sdn. Bhd. (Johor, Malaysia). Carbon dioxide was of chromatographic grade (99.995\%) and obtained from Malaysian Oxygen (Selangor, Malaysia).

SFC was carried out using a JASCO SFC system (JASCO, Easton, MD, USA) coupled with a photodiode array detector. The column used was silica $(5 \mu \mathrm{m}, 4.6 \times 250 \mathrm{~mm})$.

\subsection{SFC of Tocols}

Tocols (0.04 g) were weighed and dissolved in n-heptane, $n$-hexane, dichloromethane (DCM), ethanol or chloroform $(5 \mathrm{~mL})$, respectively. An aliquot of this mixture $(20 \mu \mathrm{L})$ was then injected into the SFC instrument. The $\mathrm{CO}_{2}$ flowrate was $2.0 \mathrm{~mL} \mathrm{~min}^{-1}$ with $0.02 \mathrm{~mL} \mathrm{~min}^{-1}$ absolute ethanol as a modifier. The column temperature was set at $50{ }^{\circ} \mathrm{C}$ and pressure $17,18,19$ and $20 \mathrm{MPa}$ respectively. 
The procedure was repeated for pressure at 18, 19 and $20 \mathrm{MPa}$. Detection of the tocols was carried out at $290 \mathrm{~nm}$.

Acknowledgments: This research did not receive any specific grant from funding agencies in the public, commercial, or not-for-profit sectors.

Author Contributions: The study was conceived by N.M.H., with advice and supported by A.K., N.M.H. performed, analysed and wrote the paper. A.K. verified the data and crosschecked the paper.

Conflicts of Interest: The authors declare no conflict of interest.

\section{References}

1. Chandan, S.; Rink, C.; Khanna, S. Palm Oil-derived natural vitamin E $\alpha$-Tocotrienol in Brain Health and Disease. J. Am. Coll. Nutr. 2010, 29, 314S-323S.

2. Abdul Hadi, N.; Ng, M.H.; Choo, Y.M.; Hashim, M.A.; Jayakumar, N.S. Performance of Choline-Based Deep Eutectic Solvents in the Extraction of Tocols from Crude Palm Oil. J. Am. Oil Chem. Soc. 2015, 92, 1709-1716. [CrossRef]

3. Majid, R.A.; Mohammad, A.W.; Choo, Y.M. Properties of residual palm pressed fibre oil. J. Oil Palm Res. 2012, 24, 1310-1317.

4. Choo, Y.M.; Ng, M.H.; Ma, A.N.; Chuah, C.H.; Hashim, M.A. Application of supercritical fluid chromatography in the quantitative analysis of minor components (carotenes, vitamin E, sterols, and squalene) from palm oil. Lipids. 2005, 40, 1429-1432. [CrossRef]

5. Ahsan, H.; Ahad, A.; Sissiqui, W.A. A review of characterization of tocotrienols from plant oils and foods. J. Chem. Biol. 2015, 8, 45-59. [CrossRef] [PubMed]

6. Ng, M.H.; Choo, Y.M.; Ma, A.N.; Chuah, C.H.; Hashim, M.A. Isolation of palm tocols using supercritical fluid chromatography. J. Chromatogr. Sci. 2004, 42, 536-539.

7. Chandrasekaram, K.; Ng, M.H.; Choo, Y.M.; Chuah, C.H. Concentration and isolation of individual vitamin e components in palm phytonutrients concentrate using high performance liquid chromatography with flourescence detection. J. Oil Palm Res. 2009, 21, 621-626.

8. Ali, S.F.; Woodman, O.L. Tocotrienol rich palm oil extract is more effective than pure tocotrienols at improving endothelium-deprendant relaxation in the presence of oxidative stress. Oxid. Med. Cell. Longev. 2015, 2015, 1-10. [CrossRef] [PubMed]

9. Goh, P.S.; Ng, M.H.; Choo, Y.M.; Amru, N.B.; Chuah, C.H. Production of tocols nanoemulsion by ultrasonication. J. Oil Palm Res. 2016, 28, 121-130.

10. Lesellier, E.; West, C. The many faces of packed column supercritical fluid chromatography-A critical review. J. Chromatogr. A 2015, 1382, 2-46. [CrossRef] [PubMed]

11. Poole, C.F. Progress in packed column supercritical fluid chromatography: Materials and methods. J. Biochem. Biophys. Methods. 2000, 43, 3-23. [CrossRef]

12. Taylor, L.T. Supercritical fluid chromatography for the 21st century. J. Supercrit. Fluids. 2009, 47, 566-573. [CrossRef]

13. Berger, T.A. Separation of polar solutes by packed column supercritical fluid chromatography. J. Chromatogr. A 1997, 785, 3-33. [CrossRef]

14. Combs, M.T.; Ashraf-Khorassani, M.; Taylor, L.T. Packed column supercritical fluid chromatography-mass spectroscopy: A review. J. Chromatogr. A 1997, 785, 85-100. [CrossRef]

15. Wilson, W.H. Direct enantiomeric resolution of ibuprofen and flurbiprofen by packed column SFC. Chirality 1994, 6, 216-219. [CrossRef]

16. Gyllenhaal, O.; Karlsson, A. Enantiomeric separations of amino alcohols by packed-column SFC on Hypercarb with L-(+)-tartaric acid as chiral selector. J. Biochem. Biophys. Methods. 2002, 54, 169-185. [CrossRef]

17. Johannsen, M. Separation of enantiomers of ibuprofen on chiral stationary phases by packed column supercritical fluid chromatography. J. Chromatogr. A 2001, 937, 135-138. [CrossRef]

18. Senorans, F.J.; Ibanez, E. Analysis of fatty acids in foods by supercritical fluid chromatography. Anal. Chim. Acta 2002, 465, 131-144. [CrossRef] 
19. Lesellier, E.; West, C.; Tchapla, A. Advantages of the use of monolithic stationary phases for modelling the retention in sub/supercritical chromatography: Application to cis/trans = carotene separation. J. Chromatogr. A 2003, 1018, 225-232. [CrossRef] [PubMed]

20. Tumera, C.; King, J.W.; Mathiassona, L. Supercritical fluid extraction and chromatography for fat-soluble vitamin analysis. J. Chromatogr. A 2001, 936, 215-237.

21. Lesellier, E. Analysis of non-saponifiable lipids by super-/subcritical fluid chromatography. J. Chromatogr. A 2001, 936, 201-214. [CrossRef]

Sample Availability: Samples of the compounds tocopherol and tocotrienols are available from the authors.

(C) 2017 by the authors. Licensee MDPI, Basel, Switzerland. This article is an open access article distributed under the terms and conditions of the Creative Commons Attribution (CC BY) license (http:/ / creativecommons.org/licenses/by/4.0/). 